\title{
Defective release of C5a related chemo-attractant activity from complement in Crohn's disease
}

\author{
J ELMGREEN, A BERKOWICZ, AND H SØRENSEN
}

From Medical Department C, Herlev Hospital, University of Copenhagen, and the Blood Bank, Rigshospitalet, University of Copenhagen, Denmark

SUMmary Complement was studied in 20 untreated cases of Crohn's disease and in 20 healthy volunteers by an in vitro activation of the cascade reaction. Total haemolytic complement was normal in all patients. In contrast, activation of the alternative pathway lead to a decreased release of $\mathrm{C5a}$ related chemo-attractant activity together with a subnormal utilisation of the main complement component C3. This abnormality of complement function was not related to the activity of the disease, site of involvement or to disease duration. The results suggest that an inadequate stimulation of important neutrophil functions may result when bacterial lipopolysaccharides and other macromolecules activating the alternative pathway penetrate the gut mucosa. A delayed clearance from the tissue of such foreign material could be a further pathogenic factor in Crohn's disease leading to granulomatous inflammation by a foreign body reaction.

The migration of neutrophils into areas of acute, experimental inflammation is markedly decreased in Crohn's disease,$^{1-3}$ and in another granulomatous condition sarcoidosis. ${ }^{4}$ This abnormality of leucocyte function is specific for these two groups of patients, ${ }^{1-3}$ and probably reflects an inadequate release of chemotactic mediators as the neutrophils themselves seem to be competent. ${ }^{1-3}$

A normal function of complement seems to be essential for the accumulation of neutrophils in inflammation. Experimental animals, deplete of complement components, are inefficient in localising granulocytes to diverse inflammatory sites. $^{5-7}$ A delayed migration of neutrophils into skin windows has been reported in $a$. patient with complete absence of the third component of complement, C3. ${ }^{8}$ The peptide $\mathrm{C} 5 \mathrm{a}$, which is released from native $\mathrm{C} 5$ during activation of complement, ${ }^{9}$ is likely to be responsible for this migration of neutrophils in inflammation. C5a and its degradation product $\mathrm{C}^{2} \mathrm{a}_{\text {des arg }}$ in highly purified preparations are potent activators of important neutrophil functions as chemotaxis ${ }^{10} 11$ and they stimulate the accumulation of neutrophils in skin window chambers. ${ }^{11}$

Address for correspondence: J Elmgreen, MD, Medical Gastroenterological Department C 107, Herlev University Hospital, DK-2730 Herlev, Denmark. Received for publication 20 August 1982
The present series of experiments was conducted to investigate the release of chemotactic factors during activation of complement in Crohn's disease.

\section{Methods}

\section{PATIENTS}

Twenty consecutive outpatients with Crohn's disease were selected for the study, excluding patients suffering from infection, rheumatic diseases, and other conditions known to affect the immune system. None had received any medical treatment within three months before the study. The diagnosis was based on typical clinical and radiological findings in eight patients and confirmed by histology in 12 patients. The disease involved the ileum in 13 patients, the ileum and the colon in five, and the colon only in two. Two patients had arthralgia. Disease activity was graded according to Harvey and Bradshaw $1980 .{ }^{12}$ Seven patients were in complete remission, whereas 13 were in an active stage (score 1-12, median 4). None of the patients showed systemic reactions as fever or loss of bodyweight, and none was confined to bed. Median disease duration was eight years, range three months to 36 years. Forty healthy volunteers with an age and sex distribution similar to the patients served as controls. 
MATERIAL AND ANTIBODIES

Gey's solution was prepared according to Wilkinson $1974^{13}$ and included disodium EDTA $(10 \mathrm{mM})$ unless otherwise stated. Nylonfibres from a Leukopak $^{(\mathrm{R})}$ apparatus (Fenwal, Deerfield, Illinois, USA) casein 'alkalilöslich' from Merck, Darmstadt, FR Germany, purified human-albumin and standard human serum from Behringwerke, Marburg, FR Germany and Sephadex ${ }^{(R)}$ G 75 gel and proteins for gel calibration from Pharmacia Fine Chemicals, Uppsala, Sweden were used. The rabbit immunoglobulins: monospecific antibodies to human $\mathrm{C} 5$ and to $\mathrm{C} 3 \mathrm{c}$ and the immunoglobulin fraction from non-immunised rabbits prepared identical to the antibodies were all from DAKO immunoglobulins, Copenhagen, Denmark, and haemolysin: rabbit antibodies to goat erythrocytes were from the Pasteur Institute, Paris, France. The assay for protein determinations was purchased from BioRad Laboratories, Richmond, USA.

\section{PREPARATION OF CHEMO-ATTRACTANTS}

For activation the freshly prepared heparin plasma $(2 \mathrm{IU} / \mathrm{ml})$ was incubated one hour at $22^{\circ} \mathrm{C}$ with sterile nylonfibres $(100 \mathrm{~g} / \mathrm{l})$, and then removed from the fibres. Nylonfibres for leukapheresis is a well established activator of alternative pathway complement. ${ }^{14}$ They were selected for the experiments to exclude the possibility of adding biological materials to the plasma which might interfere with the assay of chemo-attractant activity. As control served non-activated heparin plasma incubated without nylonfibres.

To prevent spontaneous activation of complement, disodium EDTA $(10 \mathrm{mM})$ was added to the plasma samples immediately after incubation. The samples were analysed in a fresh state or they were frozen in liquid nitrogen and kept at $-80^{\circ} \mathrm{C}$ until examined. Casein $(5 \mathrm{~g} / \mathrm{l})$ was solubilised in modified Gey's solution at $\mathrm{pH} 12$ according to Wilkinson $1974 .^{13}$

ASSESSMENT OF CHEMO-ATTRACTANT ACTIVITY Neutrophil migration was quantified by the micropore filter assay ${ }^{13}$ and the leading front method. ${ }^{15}$ Neutrophils were isolated from peripheral blood drawn in disodium EDTA (10 $\mathrm{mM}$ ). After a methyl-cellulose sedimentation leucocytes from the buffy coat were washed thrice and resuspended in Gey's solution without EDTA and including human-albumin $(20 \mathrm{~g} / \mathrm{l})$. One million cells from this suspension containing on the average $80 \%$ neutrophils was added to each $3 \mu \mathrm{m}$ Millipore ${ }^{(R)}$ filter and was incubated at $37^{\circ} \mathrm{C}$ for one hour. Results represent the median of five determinations on each of two filters.

The chemo-attractant activity of $10 \%$ dilutions of the plasma samples in Gey's solution was assessed in two series of experiments: with autologous neutrophils and with heterologous neutrophils from normal subjects. The neutrophils from normal subject were challenged with pairs of plasma preparations from patients and healthy volunteers selected by random numbers. Neutrophils run against solubilised casein and against Gey's solution acted as controls in each experiment. Eluates from Sephadex ${ }^{(R)}$ chromatography and fractions from antibody incubation studies were tested undiluted with autologous neutrophils.

CHARACTERISATION OF THE CHEMOTACTIC FACTOR Five millilitre plasma samples from three normals and from three Crohn patients were eluated from a G 75 Sephadex $^{(\mathrm{R})}$ column $\left(5 \mathrm{~cm}^{2} \times 60 \mathrm{~cm}\right)$ with Gey's solution at $10 \mathrm{ml}$ per hour. Fractions of the eluate were tested for chemo-attractant activity and for protein content by the $\mathrm{Bio}^{-\mathrm{Rad}^{(\mathrm{R})}}$ assay. The column was calibrated with proteins: ribonuclease $A$ (MW: 13 700) chymotrypsinogen A (MW: 25 000), and ovalbumin (MW: 43 000) to permit estimations of molecular weight.

Antibody to human C5 and immunoglobulins from non-immunised rabbits were incubated overnight at $4^{\circ} \mathrm{C}$ with pooled fractions of activated plasma from Sephadex ${ }^{(R)}$ chromatography eluated at the chemo-attractant peak. After incubation these fractions were tested for chemo-attractant activity in the Millipore ${ }^{(R)}$ filter assay.

\section{IMMUNOCHEMICAL DETERMINATIONS}

C3 and C5 concentrations in non-activated plasma were assessed by immunoelectrophoresis according to Laurell. ${ }^{16}$ The antibodes specific to human $\mathrm{C} 3 \mathrm{c}$ and to C5 were included in $1 \%$ agarose gel, and electrophoresis was performed at $3 \mathrm{~V} / \mathrm{cm}$ for 18 hours. Standard antigen for C3 determinations was human serum from Behring Werke with a known content of $\mathrm{C} 3 \mathrm{c}$. Concentrations of $\mathrm{C} 5$ were expressed in percent of values obtained with a plasma pool from healthy blood donors.

Crossed immunoelectrophoresis of corresponding samples of activated and of non-activated plasma were run simultaneously for the quantitative assessment of $\mathrm{C} 3$ utilisation during activation. Complete separation of native $\mathrm{C} 3$ and its conversion products was achieved in the first run at $20 \mathrm{~V} / \mathrm{cm}$ for 1.5 hours. ${ }^{17}$ The second electrophoretic dimension was performed at $3 \mathrm{~V} / \mathrm{cm}$ for 18 hours in antibody to C3c. Utilisation of $\mathrm{C} 3$ (in percent) represents the decrease in precipitation area of native $\mathrm{C} 3$. 
HAEMOLYTIC ASSAY

CH 50. Total haemolytic complement was determined by the ability of serum dilutions to lyse sheep erythrocytes coated with haemolysin. In these experiments serum was allowed to clot for one hour at room temperature.

\section{STATISTICS}

The results were evaluated with non-parametric statistics: Mann-Whitney's U test, Wilcoxon's matched-pairs signed-ranks test and Spearman's rank correlation test.

\section{Results}

The chemo-attractant activity of nylonfibre incubated plasma from Crohn's disease patients was markedly depressed as assessed with both autologous neutrophils and with neutrophils from normal subjects $(p<0 \cdot 005$, Fig. 1$)$. The responses of neutrophils to non-activated plasma from patients and from normals were not different $(\mathrm{p}>0 \cdot 10$, Fig. 2 ). Neutrophils run against casein and Gey's solution reacted identically in patients and healthy volunteers (Table 1).

The chemo-attractant activity of nylonfibre

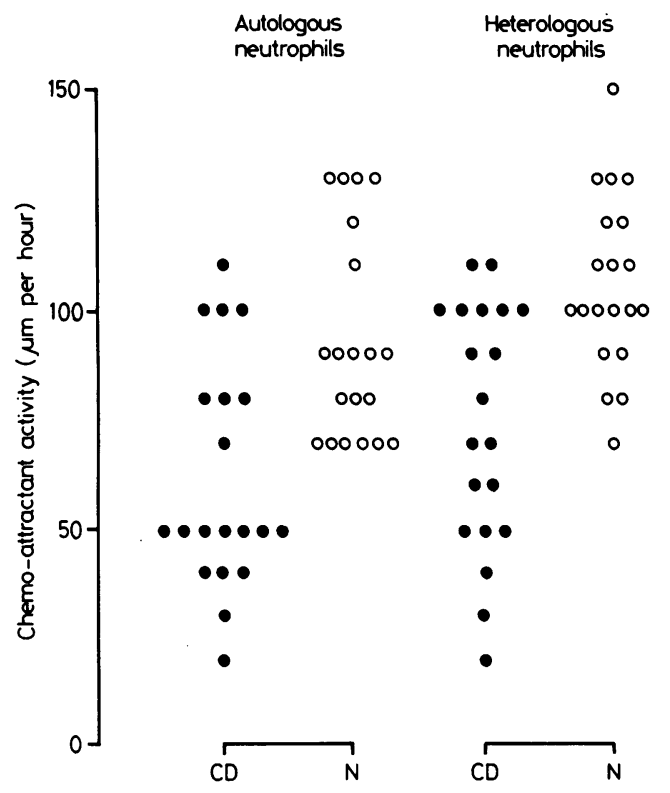

Fig. 1 Decreased chemo-attractant activity of nylonfibre incubated plasma from patients with Crohn's disease (CD) compared with reference values from normals $(N)$ ( $p<0.005)$. - Crohn's disease, ○-normals.

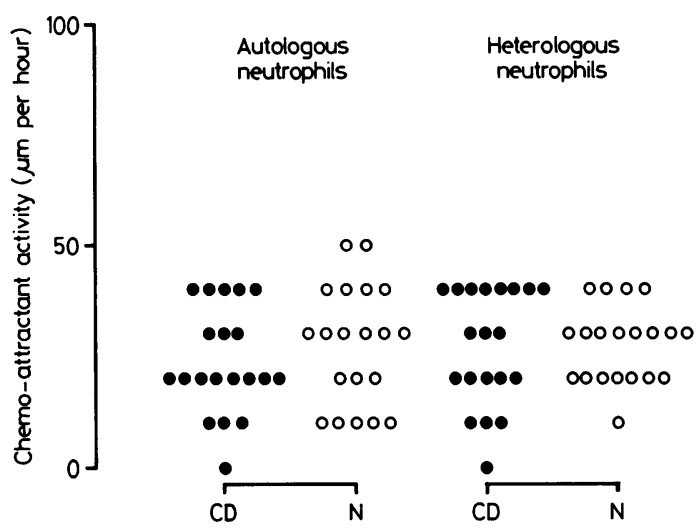

Fig. 2 The chemo-attractant activity of plasma incubated without nylonfibres was equal in patients and in healthy volunteers. - - Crohn's disease, ०-normals.

incubated plasma was confined to a single, low molecular weight, derivative from $\mathrm{C} 5$, having the characteristics of $\mathrm{C} 5 \mathrm{a} .{ }^{18} \mathrm{~A}$ single peak of chemoattractant activity appeared in fractions of nylonfibre incubated plasma eluated from the Sephadex ${ }^{(\mathrm{R})}$ column (Fig. 3). Fractions of nonactivated plasma showed no chemo-attractant activity. The factor responsible for the peak of activity had an apparent molecular weight of 15000 daltons as estimated according to Andrews. ${ }^{19}$ The biological activity eluated in the MW 15000 region was abolished by incubation with antibody specific to human C5 (Fig. 4) but remained unaffected by incubation with immunoglobulins from nonimmunised rabbits.

The utilisation (in percent) of C3 during activation was decreased in Crohn's disease patients ( $p<0.005$, Fig. 5). Concentrations of $\mathrm{C} 3$, of $\mathrm{C} 5$, and total haemolytic complement ( $\mathrm{CH} \mathrm{50)}$ were normal in the patients (Table 2). The normal level of $\mathrm{C} 3$ in Crohn's disease plasma permitted the direct comparison of the percentual $\mathrm{C} 3$ utilisation obtained in patients and normal controls.

A positive correlation was seen between the $\mathrm{C} 3$ utilisation and the release of chemo-attractant

Table 1 Neutrophil migratory response in $\mu \mathrm{m}$ per hour to casein and Gey's solution. Median values are given with ranges in parentheses.

\begin{tabular}{lll}
\hline & Casein $5 \mathrm{~g} / 1$ & Gey's solution \\
\hline Crohn's disease patients & 75 & 20 \\
$(\mathrm{n}=20)$ & $(60-100)$ & $(0-37)$ \\
Healthy volunteers & 75 & 21 \\
$(\mathrm{n}=40)$ & $(65-115)$ & $(0-35)$ \\
\hline
\end{tabular}


Fig. 3 Nylonfibre incubated plasma was eluated from a Sephadex ${ }^{(R)}$ column, and the fractions were tested for chemoattractant activity (individual values) and for protein content (curve). Both in patients and in normal controls a single peak of chemo-attractant activity appeared in MW 15000 region. Arrows indicate the eluation volume of calibration proteins: I ovalbumin, II chymotrypsinogen A, III ribonuclease $A$. Results represent median values from three experiments. - Crohn's disease, o- normals.

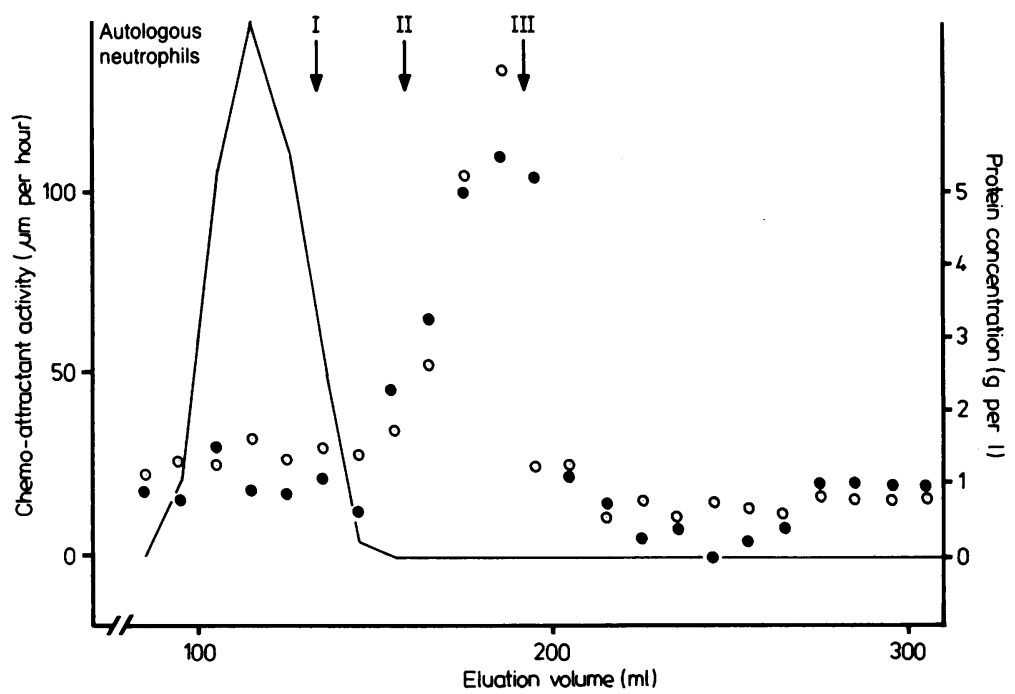

factors as assessed with autologous neutrophils $\left(r_{s}=0.484, p<0.005, n=38\right.$, Fig. 6) and with heterologous neutrophils from normal subjects $\left(r_{s}=0 \cdot 319\right.$, $\mathrm{p}<0.05, \mathrm{n}=38$ ). Trace amounts of $\mathrm{C} 3$ conversion products was detected in four samples of non-

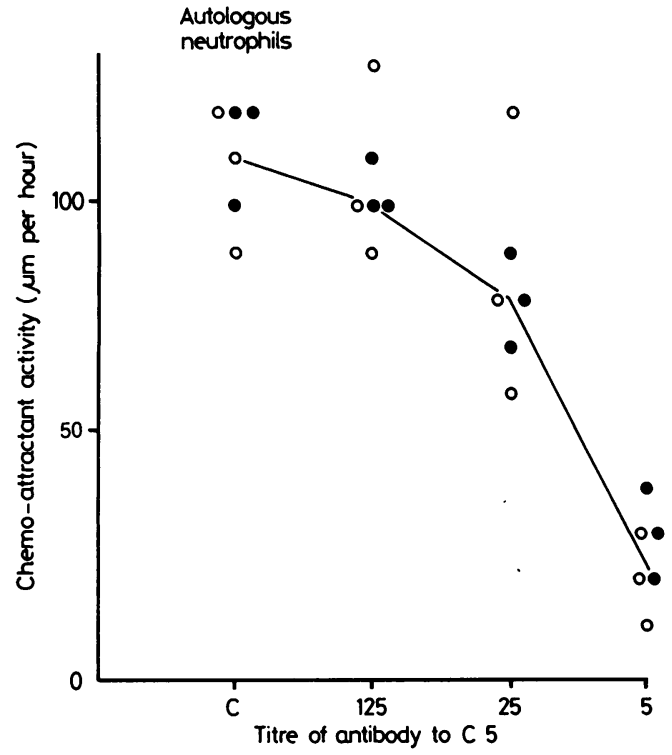

Fig. 4 Fractions of nylonfibre incubated plasma eluated from Sephadex ${ }^{(R)}$ column in MW 15000 region (chemoattractant peak) was incubated with antibody to human $C 5$ or alone, constituting control (C). Biological activity was abolished by incubation with 1 to 5 dilution of antibody, that is titre 5. - -Crohn's disease, ०-normals. activated plasma and may reflect the instability of $\mathrm{C} 3$ at $37^{\circ} \mathrm{C}$.

The C3 utilisation and the chemo-attractant activity released during nylonfibre incubation had no relation with the disease duration, disease

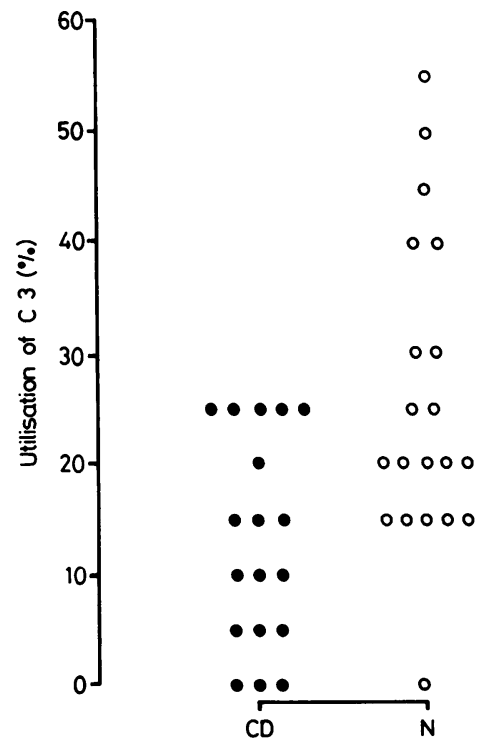

Fig. 5 Decreased utilisation (percent) of $\mathrm{C} 3$ during nylonfibre incubation of plasma from Crohn's disease (CD) compared with reference values from normals $(N)$ $(p<0.005)$. - Crohn's disease, ○-normals. 
Table 2 Median values and ranges in parentheses of plasma C3 and C5 concentrations and total haemolytic complement titres

\begin{tabular}{llll}
\hline & $\begin{array}{l}\text { C3 } \\
\mu g / m l\end{array}$ & $\begin{array}{l}\text { C5 } \\
\text { percent }\end{array}$ & $\begin{array}{l}\text { CH 50 } \\
\text { titre }\end{array}$ \\
\hline $\begin{array}{l}\text { Crohn's disease patients } \\
(\mathrm{n}=20)\end{array}$ & 920 & 104 & 32 \\
$\begin{array}{l}\text { Healthy volunteers } \\
(\mathrm{n}=20)\end{array}$ & $\begin{array}{l}(650-1370) \\
(74-180)\end{array}$ & $\begin{array}{l}91 \\
(16-64)\end{array}$ & $\begin{array}{l}32 \\
(16-32)\end{array}$ \\
\hline
\end{tabular}

activity or the involvement of the bowel $(\mathrm{p}>0 \cdot 10)$. The release of chemo-attractant activity in patients grouped according to the stage of disease activity is shown in Fig. 6.

\section{Discussion}

The present study shows a dysfunction of plasma complement in Crohn's disease. A decreased release of chemo-attractant activity was found during an in vitro activation of the alternative pathway. This abnormality was not related to the site and severity of the disease or to disease duration. The specificity of this finding has to be evaluated in further experiments including patients with infections and inflammatory conditions as rheumatoid arthritis, sarcoidosis, and ulcerative colitis.

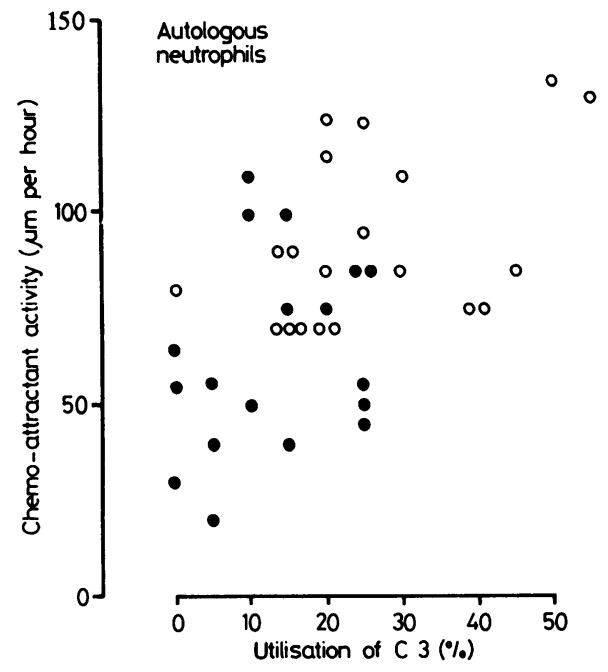

Fig. 6 Utilisation of $C 3$ during incubation with nylonwool correlated positively with the chemo-attractant activity released as assessed with autologous neutrophils $(p<0.005)$. Individual values for patients and for normal controls are given. - Crohn's disease, o-normals.

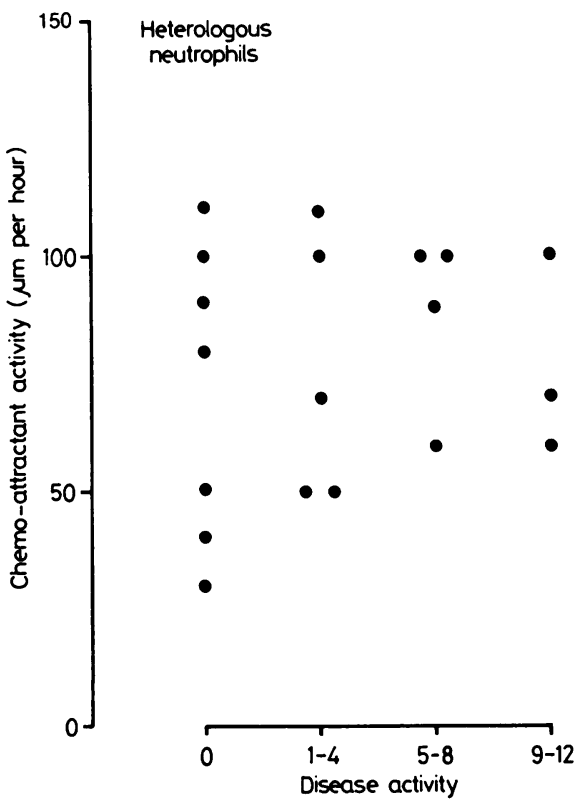

Fig. 7 Relation of chemo-attractant activity released during complement activation to stage of disease activity shown. Disease activity graded according to Harvey and Bradshaw. ${ }^{12} \bullet-$ Crohn patients.

Steroids, sulphasalazine, and its active metabolite 5 amino salicylic acid are all potent inhibitors of leucocyte motility. ${ }^{20}$ During treatment with steroids a decreased chemo-attractant activity of complement activated serum has recently been shown in Crohn's disease. ${ }^{21}$ We were able to extend these results by detecting a similar dysfunction of complement in a group of patients which had not received any drugs for at least three months.

The chemo-attractant activity released from complement in our experiments was confined to a low molecular weight derivative from $\mathrm{C} 5$, that is to $\mathrm{C} 5 \mathrm{a}$ or to its degradation product $\mathrm{C} 5 \mathrm{a}_{\text {des arg. }}$. Accordingly, the decreased release of chemoattractant activity in Crohn's disease might reflect (1) a depressed release of C5a, (2) an increased degradation of C5a to the less potent $\mathrm{C} 5 \mathrm{a}_{\mathrm{des}}$ arg by carboxypeptidase $B$ known to be present in plasma, ${ }^{18}$ or (3) the effect of cell directed inhibitors of neutrophil migration in Crohn's disease plasma. The associated finding in our patients of a subnormal utilisation of the main complement component $\mathrm{C} 3$, correlated positively to the decreased release of chemo-attractant activity, favours the hypothesis of a decreased release of C5a as explanation. Furthermore, experiments following the procedures generally outlined for the detection 
of chemotactic factor inactivators and for inhibitors of neutrophil chemotaxis has been negative in Crohn's disease. ${ }^{2}$ Immunochemical methods for a quantitative assessment of C5a has to be developed to settle this question definitely.

A primary cellular defect of the neutrophil produces histological changes of the gut in chronic granulomatous disease, closely resembling those seen in Crohn's disease ${ }^{22}$ but the two conditions are obviously dissimilar. Neutrophils from Crohn's disease patients are competent in that they behave normally in the NBT reduction test ${ }^{1323}$ and their oxygen consumption response to bacteria is normal. ${ }^{2}$ Our results indicate that in Crohn's disease a neutrophil dysfunction may be caused by an inadequate activation of neutrophil chemotaxis, and of other important cellular function of neutrophils, by C5a. This may further explain a well known decreased migration of neutrophils into skin windows in Crohn's disease. ${ }^{1-3} \mathrm{~A}$ defective phagocyte function delaying the clearance of gut luminal macromolecules, which are known to penetrate the mucosa,${ }^{24}$ could be a pathogenic factor in Crohn's disease.

The normal total haemolytic complement ( $\mathrm{CH} 50)$ in our patients confirms previous findings. ${ }^{25}$ Complement dysfunction in Crohn's disease may be confined to the alternative pathway as a diminished consumption of complement components $\mathrm{C} 3$ to $\mathrm{C} 9$ after activation of the alternative pathway, and a normal consumption after activation of the classical pathway has been reported in this condition. ${ }^{25}$

A general lack of complement components caused by the chronic complement activation present in Crohn's disease ${ }^{26} 27$ could not explain our findings. Normal concentrations of $\mathrm{C} 3$ and $\mathrm{C} 5$ in the present study are in agreement with earlier reports of normal or raised levels of $\mathrm{C}^{25-28}$ and factor $\mathrm{B}^{25-29}$ in Crohn's disease. An assessment of the functional activity of individual complement components is required to identify the factor(s) responsible for complement dysfunction in Crohn's disease.

We wish to thank $H$ Furhauge, $H$ Kargaard, L Nielsen, and D Rasmussen for excellent technical assistance. This study was supported by Jacob and Olga Madsens foundation and by Johann and Hanne Weimann née Sedorffs foundation, and by the Danish league against rheumatism.

\section{References}

1 Segal AW, Loewi G. Neutrophil dysfunction in Crohn's disease. Lancet 1976; 2: 219-21.
2 Morain CO, Segal AA, Walker D, Levi AJ. Abnormalities of neutrophil function do not cause the migration defect in Crohn's disease. Gut 1981; 22: 817-22.

3 Wandall JH, Binder V. Leucocyte functions in Crohn's disease. Gut 1982; 23: 173-80.

4 Gange RW, Black MM, Carrington P, McKerron R. Defective neutrophil migration in sarcoidosis. Lancet 1977; 2: 379-81.

5 Cochrane CG, Müller-Eberhard HJ, Aikin BS. Depletion of plasma complement in vivo by a protein of cobra venom: its effect on various immunologic reactions. J Immunol 1970; 105: 55-69.

6 DeShazo CV, McGrade MT, Henson PM, Cochrane CG. The effect of complement depletion on neutrophil migration in acute immunologic arthritis. $J$ Immunol 1972; 108: 1414-9.

7 Wiener S, Lendvai S, Rogers B, Urivetzky M, Meilman E. Nonimmune chemotaxis in vivo. Am J Pathol 1973; 73: 807-16.

8 Ballow M, Shira JE, Harden L, Yang SY, Day NK. Complete absence of the third component of complement in man. J Clin Invest 1975; 56: 703-10.

9 Atkinson JP, Frank MM. Complement. In Parker CW, ed. Clinical immunology. Philadelphia, London, Toronto: Saunders, 1980.

10 Webster RO, Hong SR, Johnston RB Jr, Henson PM. Biological effects of the human complement fragments $\mathrm{C} 5 \mathrm{a}$ and $\mathrm{C} 5 \mathrm{a}_{\text {des arg }}$ on neutrophil function. Immunopharmacology 1980; 2(3): 201-19.

11 Fernandez HN, Henson PM, Otani A, Hugli TE. Chemotactic response to human $\mathrm{C} 3 \mathrm{a}$ and $\mathrm{C} 5 \mathrm{a}$ anaphylatoxins. J Immunol 1978; 120: 109-15.

12 Harvey RF, Bradshaw JM. A simple index of Crohn's disease activity. Lancet 1980; 1: 544.

13 Wilkinson PC. Chemotaxis and inflammation. Edinburgh: Churchill Livingstone, 1974.

14 Hammerschmidt DE, Craddock PR, McCullough J, Kronenberg RS, Dalmasso AP, Jacob HS. Complement activation and pulmonary leukostasis during nylon fiber filtration leukapheresis. Blood 1978; 51: 721-31.

15 Zigmond SH, Hirsh JG. Leucocyte locomotion and chemotaxis. J Exp Med 1973; 137: 387-410.

16 Laurell CB. Quantitative estimation of proteins by electrophoresis in agarose gel containing antibodies. Anal Biochem 1966; 15: 45-52.

17 Teisberg $\mathrm{P}$. In vivo activation of $\mathrm{C} 3$ revealed by crossed immunoelectrophoresis as a parameter of immunologic activity in disease. Clin Chim Acta 1975; 62: 35-41.

18 Hugli TE, Müller-Eberhard HJ. Anaphylatoxins: C3a and C5a. Adv Immunol 1978; 26: 1-52.

19 Andrews $P$. The gel-filtration behaviour of proteins related to their molecular weights over a wide range. Biochem J 1965; 96: 595-606.

20 Rhodes JM, Bartholomew TC, Jewell DP. Inhibition of leucocyte motility by drugs used in ulcerative colitis. Gut 1981; 22: 642-7.

21 Amelio RD, Rossi P, Le Moli S, Ricci R, Montano S, Pallone F. In vitro studies on cellular and humoral chemotaxis in Crohn's disease using the under agarose gel technique. Gut 1981; 22: 566-70. 
22 Ament ME, Ochs HD. Gastrointestinal manifestations of chronic granulomatous disease. N Engl J Med 1973; 288: $382-7$.

23 Ward M. Eastwood MA. The nitroblue tetrazolium test in Crohn's disease and ulcerative colitis. Digestion 1976; 44: 179-83.

24 Walker WA. Isselbacher KJ. Uptake and transport of macromolecules by the intestine. Gastroenterology 1974; 67: 531-50.

25 Lake AM, Stitzel AE, Urmson JR, Walker WA, Spitzer RE. Complement alterations in inflammatory bowel disease. Gastroenterology 1979; 76: 374-9.

26 Teisberg P. Gjone E. Humoral immune system activity in inflammatory bowel disease. Scand J Gastroenterol 1975; 10: 545-9.

27 Nielsen H, Petersen PH, Svehag SE. Circulating immune complexes in ulcerative colitis. II. Correlation with serum protein concentrations and complement conversion products. Clin Exp Immunol 1978; 31: 81-91.

28 Hodgson HJF, Potter BJ, Jewell DP. Humoral immune system in inflammatory bowel disease: I. Complement levels. Gut 1977; 18: 749-53.

29 Feinstein PA, Kaplan SR, Thayer WR. The alternative complement pathway in inflammatory bowel disease. Gastroenterology 1976; 70: 181-5. 